\title{
AVALIAÇÃO DO MÉTODO IMUNOENZIMÁTICO (ELISA) PARA DIAGNÓSTICO DA INFECÇÃO POR Helicobacter pylori EM CRIANÇAS E ADOLESCENTES
}

\author{
Aurea PORTORREAL e Elisabete KAWAKAMI
}

RESUMO - Racional - A infecção por Helicobacter pylori é reconhecida como a causa mais freqüente de gastrite crônica em adultos e crianças. Seu diagnóstico é realizado com métodos invasivos em fragmentos de mucosa gástrica obtidos com pinça endoscópica e os não-invasivos. O método imunoenzimático constitui exame simples, rápido e de baixo custo, apresentando alta sensibilidade em pacientes adultos. Objetivo - Avaliou-se o método ELISA prospectivamente em 111 crianças e adolescentes. Material e métodos - Utilizou-se o kit "Cobas Core II" (Roche). Considerou-se Helicobacter pylori positivo quando o teste rápido da urease e a histologia resultaram ambos positivos ou quando a cultura foi positiva, e Helicobacter pylori negativo quando todos os testes foram negativos. Resultados - A idade dos 111 pacientes variou de 3 meses a 16 anos, (mediana $=9 \mathrm{a} 5 \mathrm{~m}$; média $=8 \mathrm{a} 7 \mathrm{~m} \pm 4.0)$. Infecção por Helicobacter pylori foi diagnosticada em 47,7\% (53/111). A sensibilidade da sorologia foi de $83,0 \%$ e $86,0 \%$ e a especificidade foi de $70,6 \%$ e $71,0 \%$, utilizando o ponto de corte de $7 \mathrm{U} / \mathrm{mL}$ e $5 \mathrm{U} / \mathrm{mL}$, respectivamente. Em pacientes maiores de 10 anos de idade, a sensibilidade foi de $90,6 \%$ e $96,8 \%$ e a especificidade $71,0 \%$ e $61,9 \%$, com ponto de corte de $7 \mathrm{U} / \mathrm{mL}$ e $5 \mathrm{U} / \mathrm{mL}$, respectivamente. Quando foi utilizada somente a cultura positiva como padrão ouro e ponto de corte em $5 \mathrm{U} / \mathrm{mL}$, a sensibilidade foi de 93,3\%. Conclusão - O método ELISA apresentou boa sensibilidade em crianças maiores de 10 anos, utilizando o ponto de corte de $5 \mathrm{U} / \mathrm{mL}$, porém a especificidade foi menor.

DESCRITORES - ELISA. Infecções por helicobacter. Helicobacter pylori. Criança. Adolescente.

\section{INTRODUÇÃO}

O Helicobacter pylori $(\mathrm{Hp})$ provoca resposta imunológica local e sistêmica. Os títulos de anticorpos contra o Hp, em pacientes infectados, são maiores nas classes IgG e IgA; já os títulos dos anticorpos $\operatorname{IgM}$ não diferenciam os pacientes infectados dos não-infectados; por esta razão, é mais freqüente o uso da dosagem de $\operatorname{IgG}$ e $\operatorname{IgA}$, em especial da $\operatorname{IgG}^{(48)}$. Um antígeno único não é reconhecido pelo soro de todos os pacientes, deste modo, as preparações antigênicas usadas para a detecção de anticorpos devem sempre conter múltiplos antígenos.
Vários métodos sorológicos têm sido descritos na literatura $^{(28,33,34)}$, no entanto, o método ELISA (Enzyme-linked immunosorbent assay) parece ser o mais sensível e específico em pacientes adultos de países desenvolvidos ${ }^{(18,32,40)} \mathrm{A}$ recomendação é de que o teste sorológico deve ser validado e padronizado localmente antes de seu uso ${ }^{(19)}$.

Por ser um exame não-invasivo, o teste sorológico tem sido utilizado em estudos epidemiológicos ${ }^{(3,15,24,41)}$, mas por ser infecção restrita à mucosa, em alguns casos, a estimulação antigênica pode ser lenta e resultados falso-negativos podem ocorrer em poucas semanas ou meses após nova infecção ${ }^{(39)}$.

Disciplina de Gastroenterologia Pediátrica - Universidade Federal de São Paulo - Escola Paulista de Medicina - UNIFESP-EPM, São Paulo, SP. Endereço para correspondência: Dra. Aurea Portorreal - Disciplina de Gastroenterologia Pediátrica - Rua Loefgreen, 1596 - $04040-032$ - São Paulo, SP. Brasil e-mail: aureapreal@hotmail.com 
Sensibilidade insuficiente para avaliação clínica tem sido relatada em crianças menores de 10 e $12 \operatorname{anos}^{(12,16,44)}$.

A validação dos testes sorológicos comerciais em crianças, que representam a população ideal para grandes estudos epidemiológicos, tornar-se-ia ferramenta útil no diagnóstico da infecção por Hp. O objetivo deste estudo foi avaliar a eficácia do método ELISA para diagnóstico da infecção por Hp em crianças e adolescentes.

\section{PACIENTES E MÉTODOS}

Foram avaliados prospectiva e consecutivamente 120 crianças, encaminhadas para realização de exame endoscópico ao serviço de Endoscopia Digestiva da Disciplina de Gastroenterologia Pediátrica da Universidade Federal de São Paulo - Escola Paulista de Medicina UNIFESP-EPM, São Paulo, SP, por queixas digestivas para afastar doença péptica ou para a realização de biopsias de intestino delgado. Excluíram-se pacientes com patologias crônicas extra-digestivas, imunodeprimidos ou em uso de imunossupressores, e em uso de quimioterápicos, medicamentos antiinflamatórios não-esteróides, bloqueadores $\mathrm{H} 2$ e/ou derivados nitroimidazólicos por período mínimo de 2 meses anteriores ao exame. Os responsáveis pelos pacientes foram orientados sobre os procedimentos, sendo solicitado consentimento por escrito. Preencheu-se questionário clínico. O estudo foi aprovado pela Comissão de Ética Médica da UNIFESP-EPM.

Realizou-se endoscopia digestiva alta com aparelho de videoendoscopia da marca PENTAX, modelo EG 2430. Foram realizadas seis biopsias de antro gástrico a cerca de $2 \mathrm{~cm}$ do piloro, sendo dois fragmentos para o teste rápido de urease, dois para a cultura e dois para o exame histológico. O teste rápido da urease foi realizado utilizando-se solução caseira contendo $1 \mathrm{~mL}$ de água destilada, duas gotas de fenol vermelho a $1 \%$ (como indicador de $\mathrm{pH}$ ) e $0,1 \mathrm{~g}$ de uréia $^{(42)}$. Esta solução foi preparada pelo médico endoscopista no dia do exame e mantida em temperatura ambiente. O fragmento biopsiado foi imediatamente adicionado nesta solução e a alteração na coloração foi observada por período de até 24 horas. Considerou-se positiva quando ocorreu alteração na coloração de amarelo para róseo-avermelhado. Histologia $(\mathrm{H})$ : os fragmentos para histologia foram colocados em papel de filtro e fixados em solução de formaldeído a $10 \%$. A pesquisa do $\mathrm{Hp}$ foi caracterizada como positiva com a presença de bactéria espiralada, localizada na camada mucosa do epitélio gástrico ou na superfície das células epiteliais, que se corava pelo Giemsa modificado e pela hematoxilina-eosina. Cultura (C): os fragmentos de biopsia gástrica foram introduzidos em tubo de ensaio estéril contendo $1 \mathrm{~mL}$ de solução de "brain heart infusion" (BHI) e armazenadas em geladeira de isopor para manutenção da temperatura em $-4^{\circ} \mathrm{C}$. A semeadura foi feita com a técnica do rolamento em placas com meio de cultura contendo Agar-BHI, complementado com sangue de carneiro a 5\% e meio seletivo contendo ácido nalidíxico $(2,5 \mathrm{mg} / \mathrm{mL})$, vancomicina $(2,5 \mathrm{mg} / \mathrm{mL})$ e anfotericina $\mathrm{B}(0,25 \mathrm{mg} / \mathrm{mL})$.
Todas as amostras foram manipuladas com técnicas assépticas. Após o cultivo, as placas foram colocadas em jarras para anaerobiose (Merck) com sachê produtor de microaerofilia (Anaerocult C-Merck) em amostras contendo de $5 \%$ a $7 \%$ de oxigênio e de $8 \%$ a $10 \%$ de dióxido de carbono e incubadas em estufa a $37^{\circ} \mathrm{C}$. A leitura foi realizada no $7^{\circ}$ dia e o crescimento das colônias foi caracterizado pela presença de pequenas colônias translúcidas, seguindo as estrias de inoculação. Realizaram-se como exames comprobatórios: microscopia óptica com coloração pelo método de Gram e testes da oxidase, catalase e urease. A cultura foi considerada positiva quando houve a presença de bactérias Gram negativa, curvas ou espiraladas, com reação positiva para oxidase, catalase e urease. Considerou-se negativa quando houve ausência de crescimento bacteriano após 7 dias de cultivo.

As crianças foram consideradas infectadas quando o teste rápido da urease e a histologia resultaram ambos positivos ou quando a cultura foi positiva e não-infectadas quando todos os testes foram negativos. Do total de 120 pacientes, foram excluídos 9, cujos resultados foram discordantes: 7 pacientes com teste rápido da urease (+) e $\mathrm{H}(-)$ e $\mathrm{C}(-)$ e 2 pacientes com teste rápido da urease (-), C (-) e $\mathrm{H}(+)$. O estudo foi realizado, portanto, em 111 pacientes.

Sorologia (S): no momento da punção venosa, coletaram-se $2 \mathrm{~mL}$ de sangue para realização de exame sorológico. O sangue foi centrifugado e o soro estocado em congelador a $-20{ }^{\circ} \mathrm{C}$. Utilizou-se o kit "Cobas Core II" (Roche) com método ELISA, sendo analisado em aparelho "Cobas Core II" no Laboratório Central do Hospital das Clínicas da Faculdade de Medicina da Universidade de São Paulo. O método é baseado em ensaio imunoenzimático com duas fases, permitindo a determinação quantitativa e qualitativa dos anticorpos IgG anti-Hp no soro humano. Na primeira fase, as amostras e o soro controle (positivo e negativo) foram diluídos e incubados com pérolas revestidas com antígenos $\mathrm{Hp}$ altamente purificados. Os anticorpos específicos foram fixados na pérola e a amostra sofreu lavagem para remoção do material não-fixado. Os complexos antígeno-anticorpo fixados na pérola foram detectados pelo conjugado peroxidaseanticorpo de carneiro anti IgG-humano. Nova lavagem removeu o conjugado excedente e a pérola foi incubada com solução de substrato, contendo tetrametilbenzidina e peróxido de hidrogênio. Ocorreu o desenvolvimento de coloração azulada que é proporcional a quantidade de anticorpo específico IgG anti-Hp. A reação enzimática foi interrompida pela adição de ácido e realizou-se a determinação através de absorvância com densidade óptica de $450 \mathrm{~nm}$ em aparelho de fotometria. O resultado foi considerado positivo quando a titulação foi maior ou igual a $7 \mathrm{U} / \mathrm{mL}$, conforme especificação do fabricante.

\section{Analise estatística}

Utilizou-se o teste do qui-quadrado para tabela de associação, obedecendo sempre as restrições de $\operatorname{COCHRAN}^{(11)}$ e, quando 
necessário, complementado com o teste exato de Fisher. Para se estudarem concordâncias entre respostas positivas ou negativas entre os testes, usou-se o teste para significância de mudanças de McNemar. Calcularam-se medianas e médias a título de informação. Considerouse o nível de significância em 0,05 .

\section{RESULTADOS}

A idade dos 111 pacientes variou de 3 meses a 16 anos (mediana $=9 \mathrm{a} 5 \mathrm{~m}$, média $=8 \mathrm{a} 7 \mathrm{~m} \pm 4.0)$. Destes, $45,0 \%(50 / 111)$ pertenciam ao sexo masculino e $55,0 \%(61 / 111)$ ao feminino. A idade predominante foi de 6 a a 12 a $(52,2 \%)$ (Tabela 1$)$. Houve predomínio de pacientes melanodermas $(63,0 \%$ - 70/111), em relação aos leucodermas $(37,0 \%$ - 41/111).

Dos 111 pacientes, 47,7\% (53/111) foram considerados infectados e 52,2\% (58/111) não-infectados. A prevalência da infecção por Hp foi significativamente menor na faixa etária de 0 a 6 anos $(22,6 \%)$ (Tabela 1). A idade dos 53 pacientes infectados variou de $1 \mathrm{a} 3 \mathrm{~m}$ a $15 \mathrm{a}$ $6 \mathrm{~m}($ mediana $=10 \mathrm{a} 7 \mathrm{~m}$, média $=10 \mathrm{a} \pm 3.2)$, sendo $47,5 \%(29 / 53)$ do sexo feminino e $48,0 \%(24 / 53)$ do masculino. A idade dos 58 pacientes $\mathrm{Hp}$ negativo variou de $3 \mathrm{~m}$ a $16 \mathrm{a}$ (mediana $=8 \mathrm{a} 1 \mathrm{~m}$, média $=7 \mathrm{a} 6 \mathrm{~m} \pm$ $4.4)$, sendo $55,0 \%(32 / 58)$ do sexo feminino e $45,0 \%(26 / 58)$ do masculino. Das 31 crianças de $3 \mathrm{~m}$ a 6 a de idade, 9 delas $(29,0 \%)$ eram lactentes, todos em aleitamento materno exclusivo ou misto, sendo 2 $(22,0 \%)$ Hp positivo e 7 (78,0\%) Hp negativo.

\section{Características clínicas}

Quando se avaliaram a localização e o tipo de dor, consideraramse os 80 pacientes $(72,0 \%)$ que pertenciam à faixa etária de 6 a 16 anos de idade, já que os mesmos podiam referir espontaneamente as características da dor. Dor abdominal foi relatada em 99,0\% (79/80) dos pacientes, sendo de localização epigástrica em $84,0 \%$. A presença do $\mathrm{Hp}$ em $66,0 \%$ pacientes que apresentaram dor epigástrica foi significativamente maior em relação aos $30,0 \%$ pacientes que apresentaram dor periumbilical $(P<0,05)$. O tipo de dor foi predominantemente do tipo queimação em $77,6 \%$. Dor noturna que

TABELA 1 - Freqüência da infecção pelo Hp em crianças de diversas faixas etárias

\begin{tabular}{lcccccc}
\hline Hp & \multicolumn{2}{c}{ Positivo } & \multicolumn{2}{c}{ Negativo } & \multicolumn{2}{c}{ Total } \\
Faixa etária & n & \% & n & \% & n & \% \\
\hline $0 \neg 6(\mathrm{~A})$ & 7 & $22,6^{*}$ & 24 & 77,0 & 31 & 22,58 \\
$6 \neg 12(\mathrm{~B})$ & 34 & 58,6 & 24 & 41,0 & 58 & 58,62 \\
$12 \neg 16(\mathrm{C})$ & 12 & 54,5 & 10 & 45,0 & 22 & 54,75 \\
TOTAL & 53 & & 58 & & 111 & 47,75 \\
\hline
\end{tabular}

$\mathrm{c} 2$ calc $=11.026^{*}$ Comparações: $\mathrm{A}$ vs BC c2 calc $=10.920^{*} ; \mathrm{C}$ vs B c2 calc $=0.106$ desperta o paciente foi relatado em 41,2\% (33/80). Outros sintomas relatados foram: náuseas em $63,3 \%$, vômitos em $71,7 \%$, plenitude pós-prandial em $35,1 \%$, sensibilidade abdominal em $37,8 \%$, flatulência em $20,7 \%$ e regurgitação em $3,6 \%$. História familiar de doença péptica esteve presente em $60 / 111$ pacientes $(54,0 \%)$, sendo referida em $56,6 \%$ (30/53) dos pacientes Hp positivo e 51,6\% (30/58) dos Hp negativo. Em relação aos achados endoscópicos, presença do $\mathrm{Hp}$ foi significativamente maior na vigência de exame endoscópico alterado. Hp foi positivo em 80,5\% (29/36) das gastrites, em 20,0\% (1/5) das esofagites, em 100,0\% (6/6) das úlceras duodenais e em 50,0\% (1/2) das duodenites.

\section{Sorologia}

Dos 111 pacientes, 55,0\% (61/111) apresentaram títulos de anticorpos anti-Hp maiores de $7 \mathrm{U} / \mathrm{mL}$ e 45,0\% (50/111) apresentaram títulos menores de $7 \mathrm{U} / \mathrm{mL}$. A sensibilidade da sorologia foi de $83,0 \%$ (IC95\% 76\% - 90\%) especificidade de 70,6\% (IC95\% 62\% - 78,8\%), VPP de $72,0 \%$ e VPN de $82,0 \%$ (Tabela 2).

TABELA 2 - Sensibilidade e especificidade da sorologia em 111 pacientes

\begin{tabular}{|c|c|c|c|c|c|c|}
\hline \multirow[t]{3}{*}{ Sorologia } & \multicolumn{6}{|c|}{ Helicobacter pylori } \\
\hline & \multicolumn{2}{|c|}{ Positivo } & \multicolumn{2}{|c|}{ Negativo } & \multicolumn{2}{|c|}{ Total } \\
\hline & $\mathbf{n}$ & $\%$ & $\mathbf{n}$ & $\%$ & $\mathbf{n}$ & $\%$ \\
\hline Positivo & 44 & 83,0 & 17 & 29,0 & 61 & 55,0 \\
\hline Negativo & 9 & 17,0 & 41 & 71,0 & 50 & 45,0 \\
\hline Total & 53 & 100,0 & 58 & 100,0 & 111 & 100,0 \\
\hline
\end{tabular}

Dividindo os pacientes em dois grupos etários a partir de 10 anos, o que tornou a amostra mais homogênea, observou-se em menores de 10 anos de idade sensibilidade de $71,4 \%$ com ponto de corte de $5 \mathrm{U} / \mathrm{mL}$ e $7 \mathrm{U} / \mathrm{mL}$, e $75,6 \%$ e especificidade de $70,2 \%$ e $75,6 \%$ com ponto de corte de $5 \mathrm{U} / \mathrm{mL}$ e $7 \mathrm{U} / \mathrm{mL}$, respectivamente. Em maiores de 10 anos, a sensibilidade foi de $90,6 \%$ e $96,8 \%$ e a especificidade de $71,0 \%$ e $61,9 \%$, com ponto de corte de 7 e $5 \mathrm{U} / \mathrm{mL}$, respectivamente.

Analisando a sensibilidade da sorologia, levando-se em consideração somente a cultura positiva como padrão ouro, a sensibilidade foi de $86,6 \%$; porém utilizando como ponto de corte o valor de $5 \mathrm{U} / \mathrm{mL}$ a sensibilidade aumentou para $93,0 \%$.

Os pacientes Hp positivo apresentaram variação de títulos de $0,00 \mathrm{U} / \mathrm{mL}$ a $857,77 \mathrm{U} / \mathrm{mL}$, com média de $111,19 \mathrm{U} / \mathrm{mL} \pm 146,8$. Em nove pacientes, os resultados foram falso-negativos. Nos pacientes Hp negativo, os títulos de anticorpos variaram de $0,00 \mathrm{U} / \mathrm{mL}$ a 85,80 $\mathrm{U} / \mathrm{mL}$ com média de $16,43 \mathrm{U} / \mathrm{mL} \pm 27,58$. Os resultados falso-positivos 
ocorreram em 17 pacientes. A concentração de IgG em pacientes Hp positivo de acordo com as diferentes faixas etária foram: 0 a $6 \mathrm{a}$ (mediana $=40,00 \mathrm{U} / \mathrm{mL}$, variação $0,00 \mathrm{U} / \mathrm{mL}$ - 199,60 U/mL), 6 a 12a (mediana $=39,50 \mathrm{U} / \mathrm{mL}$, variação $0,00 \mathrm{U} / \mathrm{mL}-857,77 \mathrm{U} / \mathrm{mL}$ ), 12 a $16 \mathrm{a}$ (mediana $=102,40 \mathrm{U} / \mathrm{mL}$, variação $1,30-294,40 \mathrm{U} / \mathrm{mL}$ ). Todas as seis crianças com úlcera duodenal apresentaram $\mathrm{Hp}$ positivo com sorologia positiva (59,26 U/mL, 68,60 U/mL, 111,47 U/mL, 148,68 U/mL, 294,36 U/ $\mathrm{mL}, 857,77 \mathrm{U} / \mathrm{mL})$.

\section{DISCUSSÃO}

Foram estudados 111 pacientes de idade compreendida entre 3 meses a 16 anos, incluindo lactentes, ao contrário de outros trabalhos com casuística similar ou maior que a presente, que não incluíram crianças menores de 2 anos de $\operatorname{idade}^{(1,25,44,49,50)}$. A distribuição de idade dos pacientes infelizmente não foi uniforme, prevalecendo a faixa etária de 6 a 12 anos $(52,0 \%)$.

A infecção por Hp foi detectada em $61,0 \%$ das crianças que apresentaram dor abdominal, estando significativamente mais presente em pacientes com dor na região epigástrica, comparado com aqueles com dor na região periumbilical. Apesar da infecção não ser associada com sintomas específicos, alguns autores relatam que dor epigástrica, dor em queimação, dor noturna, sensação de plenitude pós-prandial, vômitos e náuseas estão relacionados com a infecção pelo $\mathrm{Hp}^{(8,23,25,27,45)}$. A mediana da idade das crianças não-infectadas desta série foi menor que as infectadas, sendo a prevalência de Hp significativamente menor na faixa etária de $3 \mathrm{~m}$ a $6 \mathrm{a}(22,6 \%)$ quando comparado com crianças maiores $(58,6 \%$ de 6 a 12 a e $54,5 \%$ de 12 a 16a) conforme observado também em outros estudos ${ }^{(24,43,49)}$. Quanto ao sexo, não houve diferença estatisticamente significativa entre os pacientes Hp positivo e Hp negativo, fato já observado por outros autores $^{(4,26,35,36,37,51,52,54)}$. A maioria dos pacientes desta casuística com gastrite apresentou infecção por Hp (80,5\%), fato descrito por outros autores ${ }^{(10,13)}$, e todos os pacientes com úlcera duodenal eram Hp positivo.

Os testes sorológicos, apesar de descritos logo após a descoberta do $\mathrm{Hp}^{(31,38)}$, ainda se encontram em desenvolvimento. Diversos métodos têm sido utilizados, incluindo a hemaglutinação e a fixação do complemento. Optou-se pelo método ELISA por ser o mais amplamente usado devido a sua simplicidade de execução e baixo custo $^{(22)}$. O desempenho dos testes sorológicos pode variar, dependendo da natureza do antígeno utilizado ${ }^{(5,9,28,56)}$ da idade, raça e do valor escolhido para ponto de corte $\mathrm{e}^{(6,28,32,44)}$ devendo ser validado em cada região geográfica.

Pouco se conhece sobre o desenvolvimento de anticorpos antiHp em crianças menores de 24 meses de idade. A presença de IgA específica presente no leite humano poderia ter importante papel no retardo do início da infecção. Nos nove lactentes em uso de aleitamento materno exclusivo ou misto, apenas dois (22,2\%) tinham a infecção. Das duas crianças infectadas, uma apresentou sorologia negativa $(4,7 \mathrm{U} / \mathrm{mL})$, com valor muito próximo do ponto de corte, isto podendo ser justificado pela não-seroconversão, o que dificulta a validação do teste nesta faixa etária ${ }^{(7,20)}$. Além disso, já que a infecção atinge somente a mucosa, a estimulação antigênica pode estar diminuída, enfatizando a importância dos valores do ponto de corte $^{(38)}$. O valor estabelecido em adultos como ponto de corte, para determinar a presença ou ausência da infecção por Hp através da sorologia, não é apropriado para o uso em crianças ${ }^{(19)}$ devido a resposta humoral ser diferente. Deve-se buscar o ponto de corte nesta faixa etária, tendo como objetivo boa especificidade e sensibilidade para o método ${ }^{(6,13,14)}$. Resultado falso-negativo pode acontecer desde poucas semanas ou inclusive meses após infecção por $\mathrm{Hp}$, até que o paciente tenha resposta imune. Dentre as sete crianças Hp negativo, uma lactente de 1a $5 \mathrm{~m}$ apresentou sorologia positiva $(56,60 \mathrm{U} / \mathrm{mL})$. Resultado falso-positivo pode aparecer após a erradicação espontânea, mas a soroconversão pode ocorrer entre 3 e 6 meses de idade em filhos de mães soropositivas ${ }^{(2,21)}$.

Embora o método ELISA tenha sido considerado de alta sensibilidade e especificidade para o diagnóstico da infecção por Hp em adultos ${ }^{(47,53,55)}$, resultados discrepantes têm sido encontrados em crianças. O teste sorológico no presente estudo apresentou sensibilidade de $83,0 \%$, à semelhança de outros autores ${ }^{(13,27,50)}$ e inferior a outros ${ }^{(1,10)}$. Ao se compararem os resultados desta série com as diversas faixas etárias com outro estudo similar utilizando o mesmo kit de sorologia, realizado em Belo Horizonte, $\mathrm{MG}^{(44)}$, verificou-se que a sensibilidade foi superior nas faixas etária de 0 a 6 anos $(71,4 \%)$ e 6 a 12 anos $(85,2 \%)$ e inferior entre 12 e 16 anos $(83,3 \%)$, comparados a valores de sensibilidade de 2 a 6 anos (44,4\%), 7 a 11 anos $(76,7 \%)$ e de 12 a 16 anos $(93,1 \%)$. A baixa sensibilidade na idade de 12 a 16 anos verificada no presente estudo, pode estar relacionada ao pequeno número de pacientes estudados, mas quando se diminui o ponto de corte em $30 \%$ do valor sugerido pelo fabricante ( $5 \mathrm{U} / \mathrm{mL}$ ) observa-se incremento da sensibilidade de $90,6 \%$ para $96,8 \%$ em pacientes maiores de 10 anos.

A especificidade, no entanto, foi muito inferior quando comparada com os trabalhos dos mesmos autores ${ }^{(13,27,50)}$. Vale ressaltar que a comparação dos resultados desta casuística com a literatura é dificultada pela utilização de diferentes métodos com diferentes preparados antigênicos ou diferentes conteúdos de determinante antigênico. JENSEN et al. ${ }^{(29)}$ analisaram oito testes sorológicos comerciais e observaram que a sensibilidade variou de $71,0 \%$ a $94,0 \%$ e a especificidade de $65,0 \%$ a $83,0 \%$. No presente estudo, encontrou-se grande número de resultados falso-positivos ${ }^{(18)} \mathrm{em}$ pacientes com idade compreendida entre 1a $5 \mathrm{~m}$ e $15 \mathrm{a} 10 \mathrm{~m}$ e títulos entre $8,52 \mathrm{U} / \mathrm{mL}$ e $85,80 \mathrm{U} / \mathrm{mL}$. Isto poderia ser decorrente da reação cruzada, da baixa sensibilidade da cultura ou à infecção pregressa, onde ainda persistem 
títulos sorológicos elevados ${ }^{(15,29,3046)}$. Ao se compararem as concentrações de $\mathrm{IgG}$, verificam-se que os títulos foram superiores aos de OLIVEIRA et al. ${ }^{(44)}$. Fatores como duração mais prolongada da infecção, presença de mais cepas ou mais carga bacteriana ${ }^{(57)}$ poderiam interferir nos resultados.

VANDENPLAS et al. ${ }^{(57)}$, utilizando somente a cultura positiva como referência, observaram $\mathrm{S}=96,0 \%, \mathrm{E}=96,0 \%$. Quando se analisou a sensibilidade da sorologia, levando-se em consideração somente a cultura positiva como padrão ouro, a sensibilidade foi de $86,6 \%$.

Se fosse utilizada a cultura como padrão ouro, encontrar-se-iam quatro resultados falso-negativos, porém dois destes pacientes apresentaram títulos próximos ao ponto de corte $(5,94 \mathrm{U} / \mathrm{mL}$ e 6,98 $\mathrm{U} / \mathrm{mL}$ ) e se o mesmo fosse diminuído para $5 \mathrm{U} / \mathrm{mL}$ restariam dois resultados falso-negativos, o que incrementaria a sensibilidade $86,6 \%$ para $93,3 \%$. Os pacientes com cultura positiva apresentaram concentrações de IgG maiores que os pacientes com cultura negativa, fato já observado por outros autores ${ }^{(17)}$.

Os resultados do teste sorológico poderiam ser mais precisos, desenvolvendo-se método próprio com antígenos encontrados na região em estudo. KHANNA et al. ${ }^{(33)}$ desenvolveram um ELISA para deteção de IgG em crianças, na África do Sul, e compararam com três testes comerciais, encontrando sensibilidade de $91,4 \%$ versus $78,0 \%$, observando que os testes comerciais não são aplicáveis em regiões geográficas diferentes daquelas onde o teste foi desenvolvido, padronizado e validado.

Conclui-se que o método imunoenzimático (ELISA) para diagnóstico da infecção por Helicobacter pylori foi mais eficiente em crianças acima de 10 anos de idade, utilizando o ponto de corte de 5,0 $\mathrm{U} / \mathrm{mL}(96,8 \%)$, mas a especificidade foi baixa $(61,9 \%)$, sugerindo que diante de resultado de sorologia positivo, seja realizado outro exame para confirmação diagnóstica.

O ideal seria se existisse padrão ouro com mais técnicas sensíveis e específicas para a avaliação da sorologia, desde que utilizando somente a cultura positiva com o ponto de corte de $5 \mathrm{U} / \mathrm{mL}$, houve um grande incremento na sensibilidade $(93,3 \%)$.

\section{AGRADECIMENTO}

Ao Dr. Cristovão Luis Mangueira e membros do Laboratório de Imunologia do Hospital das Clínicas da Faculdade de Medicina da Universidade de São Paulo, pelo apoio recebido na realização deste estudo.

Portorreal A, Kawakami E. Evaluation of enzyme-linked immunosorbent assay for the diagnosis of Helicobacter pylori infection in children and adolescents. Arq Gastroenterol 2002;39(3):198-203.

ABSTRACT - Background - Helicobacter pylori infection is recognized as the most frequent cause of chronic gastritis in adults and children. The diagnosis is accomplished with invasive methods in fragments of endoscopic gastric biopsies and non-invasive methods. The enzyme-linked immunosorbent assay constitutes a simple, fast exam and of low cost with high sensibility in adult patients. Aim - The purpose of this study was to evaluate the ELISA method for the infection diagnosis for Helicobacter pylori in children and adolescents using the Cobas Core II kit (Roche). Helicobacter pylori was positive when the rapid urease test and the histology were both positive or when the culture was positive and Helicobacter pylori negative when all the tests were negative. Patients/Methods - Eleven hundred patients were studied, their age ranged from 3 months and 16 years, (mean $=8 \mathrm{y} 7 \mathrm{~m} \pm 4.0 ;$ median $=9 \mathrm{y} 5 \mathrm{~m})$. Helicobacter pylori infection was diagnosed in 47.7\% (53/111). Result Sensitivity was $83.0 \%$ and $86.0 \%$; specificity was $70.6 \%$ and $71.0 \%$, using the cutoff of $7 \mathrm{U} / \mathrm{mL}$ and $5 \mathrm{U} / \mathrm{mL}$, respectively. When only the positive culture was used as gold standard and the cutoff of $5 \mathrm{U} / \mathrm{mL}$, the sensitivity was $93.3 \%$. In patients older than 10 years, the sensibility was $90.6 \%$ and $96.8 \%$; specificity was $71.0 \%$ and $61.9 \%$, with the cutoff of $7 \mathrm{U} / \mathrm{mL}$ and $5 \mathrm{U} / \mathrm{mL}$, respectively. Conclusion - ELISA method had good sensitivity in children older than 10 years, using the cutoff $5 \mathrm{U} / \mathrm{mL}$, but the specificity was low.

HEADINGS - Enzyme-linked immunosorbent assay. Helicobacter infections. Helicobacter pylori. Child. Adolescent.

\section{REFERÊNCIAS BIBLIOGRÁFICAS}

1. Blecker U, Lanciers S, Hauser B, Vandenplas Y. Diagnosis of Helicobacter pylor infection in adults and children using the Malakit Helicobacter pylori, a commercially available enzyme-linked immunosorbent assay. J Clin Microbiol 1993;31:1770-3

2. Blecker U, Lanciers S, Hauser B, Vandenplas Y. The prevalence of Helicobacter pylori positivity in a symptom-free population, aged 1 to 40 years. $\mathrm{J}$ Clin Epidemiol 1994;47:1095-8.

3. Blecker U, Lanciers S, Keppens E, Vandenplas Y. Evolution of Helicobacter pylori positivity in infants born from positive mothers. J Pediatric Gastroenterol Nutr 1994;19:87-90.

4. Blecker U, Mehta DI, Vandenplas Y. Sex ratio of Helicobacter pylori infection in childhood [letter]. Am J Gastroenterol 1994;89:293.
5. Bodhidatta L, Hoge CW, Churnratanakul S, Nirdnoy W, Sampathanukul P, Tungtaem C, Raktham S, Smith CD, Escheverria P. Diagnosis of Helicobacter pylori infection in a developing country: comparison of two ELISAs and a seroprevalence study. J Infect Dis 1993;68:1549-53.

6. Carmorlinga-Ponce M, Torres J, Perez-Perez G, Leal-Herrera Y, Gonzalez-Ortiz B, Madrazo de la Garza A, Gomez A, Muñoz O. Validation of a serologic test for the diagnosis of Helicobacter pylori infection and the immune response to urease and CagA in children. Am J Gastroenterol 1998;93:1264-70.

7. Casswall TH, Nilsson HO, Bergstrom M, Aleljung P, Wadstrom T, Dahlstrom AK, Albert MJ, Sarker SA. Evaluation of serology, 13C breath test and polymerase chain reaction of stool samples to detect Helicobacter pylori in Bangladeshi children. J Pediatr Gastroenterol Nutr 1999;28:31-6.

8. Cave DR, Hoffman JS. Management of Helicobacter pylori infection in ulcer disease. Hospital Practice 1996;31: 63-75. 
9. Chacon EP, Correnti M, Salma N, Serrano N, Piñeiro R, Cavazza ME, Urrestarazu MI. Ensayo inmunoenzimático para el serodiagnóstico de la infección de Helicobacter pylori. Gen 1995;49:208-11.

10. Chong SKF, Lou Q, Asnicar MA, Zimmerman SE, Croffie JM, Lee CH, Fitzgerald JF. Helicobacter pylori infection in recurrent abdominal pain childhood: comparison of diagnostic test and therapy. Pediatrics 1995;96:211-5.

11. Cochran WC. Some methods for strengthening the common 2-test. Biometrics 1954;10:417-51.

12. Corvaglia L, Bontems P, Devaster JM, Heimann P, Glupczynski Y, Keppens E, Cadranel S. Accuracy of serology and 13C-urea breath test for detection of Helicobacter pylori in children. Pediatr Infect Dis J 1999;18:976-9.

13. Crabtree JE, Mahony MJ, Taylor DJ, Heatley RV, Littlewood JM, Tompkins DS. Immune response to Helicobacter pylori in children with recurrent abdominal pain. J Clin Pathol 1991;44:768-71.

14. De Giacomo C, Fiocca R, Villani L, Lisato L, Licardi G, Diegoli N, Donadoni A, Maggiore G. Helicobacter pylori infection and chronic gastritis: clinical, serological and histologic correlations in children treated with amoxicilin and colloidal bismuth subcitrate. J Pediatr Gastroenterol Nutr 1990;11:310-6.

15. Drumm B, Perez-Perez GI, Blaser MJ, Sherman PM. Intrafamilial clustering of Helicobacter pylori infection. N Engl J Med 1990;322:359-63.

16. Drumm B, Koletzko S, Oderda G. On behalf of the european paediatric task force on Helicobacter pylori. - Helicobacter pylori infection in children: a consensus statement. J Pediatr Gastroenterol Nutr 2000;30:207-13.

17. Edwards CN, Douglin CP, Prussia PR, Garriques SA, Levett PN. Epidemiology of Helicobacter pylori infection in Barbados. W I Med J 1997;46:3-7.

18. Evans DJ Jr, Evans DJ, Graham DY, Klein PD. A sensitive and specific serological test for detection of Campylobacter pylori. Gastroenterology 1989;96:1004-8.

19. Feldman RA, Evans SJW. Accuracy of diagnostic methods used for epidemiological studies of Helicobacter pylori. Aliment Pharmacol Ther 1995;9:21-31.

20. Glupczynski Y. Microbiological and serological diagnostic tests for Helicobacter pylori: an overview. Acta Gastroenterol Belg 1998;61:321-6.

21. Gold BD, Kanna B, Huang LM, Lee CY, Banatvala N. Helicobacter pylori acquisition in infancy after decline of maternal passive immunity. Pediatr Res 1997;41:641-6.

22. Goossens H, Glupczynski Y, Burette A, Van Den Boore C, Butzler JP. Evaluation of a commercially available second generation immunoglobulin $\mathrm{G}$ enzyme immunoassay for detection of Helicobacter pylori infection. J Clin Microbiol 1992;30:176-80

23. Gormally SM, Prakash N, Durnin MT, Daly LE, Clyne M, Kierce BM, Drumm B Association of symptoms with Helicobacter pylori infection in children. J Pediatr 1995;126:753-6

24. Graham DY, Adam E, Reddy GT, Argawal JP, Argawal R, Evans DJ Jr, Malaty HM, Evans DG. Seroepidemiology of Helicobacter pylori infection in India. Comparison of developing and develop countries. Dig Dis Sci 1991;36:1084-8.

25. Gremse DA, Sacks AI. Symptoms of gastritis due to Helicobacter pylori in children. South Med J 1996;89:278-81.

26. Hardikar W, Feekery C, Smith A, Oberklaid F, Grimwood K. Helicobacter pylori and recurrent abdominal pain in children. J Pediatr Gastroenterol Nutr 1996;22:148-52

27. Heldenberg D, Wagner Y, Heldenberg E, Keren S, Auslaender L, Kaufshtein M, Tenebaum, G. The role of Helicobacter pylori in children with recurrent abdominal pain. Am J Gastroenterol 1995;90:906-9.

28. Hoek FJ, Noach LA, Raws EAJ, Tytgat GNJ. Evaluation of the performance of commercial test kits for detection of Helicobacter pylori antibodies in serum. J Clin Microbiol 1992;30:1525-8.

29. Jensen AK, Andersen LP, Wachmann CH. Evaluation of eight commercial kits for Helicobacter pylori IgG antibody detection. APMIS 1993;101:795-801.

30. Johansen HK, Norgaard A, Andersen LP, Jensen P, Nielsen H, Hoiby N. Crossreactive antigens shared by Pseudomonas aeruginosa, Helicobacter pylori, Campylobacter jejuni and Haemophilus influenzae may cause false-positive titers of antibody to H. pylori. Clin Diagn Lab Immunol 1995;2:149-55.

31. Jones DM, Lessells AM, Eldridge J. Campylobacter-like organisms on the gastric mucosa: culture, histology and serological studies. J Clin Pathol 1984;37:1002-6.

32. Jones DM, Eldridge J, Fox AJ, Sethi P, Whorwell PJ. Antibody to the gastric Campylobacter-like organism ("Campylobacter pyloridis") - clinical correlation and distribution in the normal population. J Med Microbiol 1986;22:57-62.

33. Khanna B, Cutler A, Israel NE, Perry M, Lastovica A, Fields PI, Gold BD. Use caution with serologic testing for Helicobacter pylori infection in children. J Infect Dis 1998;178:460-5.

34. Loy CT, Irwing LM, Katelaris PH, Talley NJ. Do commercial serological kits for Helicobacter pylori infection differ in accuracy? A meta-analysis. Am J Gastroenterol 1996;91:1138-44.
35. Maherzi A, Fendri $\mathrm{C}$, Ben Jilani $\mathrm{S}$, Bousnina $\mathrm{S}$. L'infection symptomatique à Helicobacter pylori: ètude prospective des aspects èpidémiologiques, diagnostiques et thérapeutiques chez 1'enfant en Tunisie. Arch Pédiatr 1996;3:329-34.

36. Malaty HM, Evans DG, Evans DJ Jr, Graham DY. Helicobacter pylori in hispanics: comparison with blacks and whites of similar age and socioeconomic class. Gastroenterology 1992;103:813-6.

37. Malaty HM, Graham DY. Importance of childhood socioeconomic status on the current prevalence of Helicobacter pylori infection. Gut 1994;35:742-5.

38. Marshall BJ, Mcgechie DB, Francis GJ, Utley PJ. Pyloric campilobacter serology. Lancet 1984;2:281.

39. Mégraud F. Advantages and disadvantages of current diagnostic test for the detection of Helicobacter pylori. Scand J Gastroenterol 1996;31:57-62.

40. Newell DG. Identification of the outer membrane proteins of C. pyloridis and $C$ jejuni. J Gen Microbiol 1987;133:163-70.

41. Oderda G, Vaira D, Holton J, Ainley C, Altare F, Boero M, Smith A, Ansaldi N Helicobacter pylori in children with peptic ulcer and their families. Dig Dis Sci 1991;36:572-6.

42. Ogata SK, Kawakami E, Pedroso MZ, Patrício FRS, Santos AM. Evaluation of invasive and non-invasive methods for the diagnosis of Helicobacter pylori infection in symptomatic children and adolescents. São Paulo Med J 2000;119:67-71.

43. Oliveira AMR, Queiroz DMM, Rocha GA, Mendes EN. Seroprevalence of Helicobacter pylori infection in children of low socioeconomic level in Belo Horizonte, Brazil. Am J Gastroenterol 1994;89:2201-4.

44. Oliveira AMR, Rocha GA, Queiroz DMM, Mendes EN, Carvalho AST, Ferrari TCA, Nogueira AMMF. Evaluation of enzyme-linked immunosorbent assay for the diagnosis of Helicobacter pylori infection in children from different age groups with and without duodenal ulcer. J Pediatr Gastroenterol Nutr 1999;28:157-61.

45. Patchett S, Beattie S, Leen E, Keane C, O'Morain C. Eradicating Helicobacter pylori and symptoms of non-ulcer dyspepsia. Br Med J 1991;303:1238-40.

46. Perez-Perez GI, Hopkins JA, Blaser MJ. Lipopolysaccharide structures in enterobacteriaceae, Pseudomonas aeruginosa and Vibrio cholerae are immunologically related to Campylobacter spp. Infect Immun 1986;51:204-8.

47. Plebani M, Basso D, Cassaro M, Brigato L, Scrigner M, Toma A, Di Mario F, Rugge M. Helicobacter pylori serology in patients with chronic gastritis. Am J Gastroenterol 1996;91:954-8.

48. Rathbone BJ, Wyatt JI, Worsley BW, Shires SE, Trejdosiewicz LK, Heatley RV, Losowsky MS. Systemic and local antibody responses to gastric Campylobacter pyloridis in non-ulcer dyspepsia. Gut 1986;27:642-7.

49. Rocha GA, Queiroz DM, Mendes EN, Carvalho AS, Oliveira AM, Moura SB. Serodiagnosis of Helicobacter pylori infection in children by an indirect immunofluorescense test. J Pediatr Gastroenterol Nutr 1993;16:247-51.

50. Rocha GA, Queiroz DMM, Oliveira AMR, Mendes EN, Moura SB, Carvalho AST, Oliveira CA. Serodiagnosis of Helicobacter pylori $(\mathrm{Hp})$ infection by second generation ELISA test: comparison between adults and children [abstract]. Gut 1996;39 Suppl 2:A121.

51. Rutigliano V, Ierardi E, Francavilla R, Castellaneta S, Margiotta M, Amoruso A, Marrazza E, Traversa A, Panella C, Rigillo N, Francavilla A. Helicobacter pylori and nonulcer dyspepsia in childhood: clinical pattern, diagnostic techniques and bacterial strains. J Pediatr Gastroenterol Nutr 1999;28:296-300.

52. Sarmiento QF, Chávez CE, Pizarro MB, Kakarieka WE, Vial PMT, Gotteland RM. Infección por Helicobacter pylori y daño gástrico en niños de nivel socioeconómico bajo. Rev Chil Pediatr 1997;68:251-5.

53. Sobola GM, Crabtree JE, Pentith JA, Rathbone BJ, Shallcross TM, Wyatt JI, Dixon MF, Heatley RV, Axon ATR. Screening dyspepsia by serology to Helicobacter pylori. Lancet 1991;338:94-6.

54. Staat MA, Kruszon-Moran D, Macquillan GM, Kaslow RA. A population-based serologic survey of Helicobacter pylori infection in children and adolescents in the United States. J Infect Dis 1996;174:1120-3.

55. Thijs JC, Van Zwet AA, Thijs WJ, Oey HB, Karrenbeld A, Stellaard F, Luijt DS, Meyer BC, Kleibeuker JH. Diagnostic tests for Helicobacter pylori: a prospective evaluation of their accuracy, without selecting a single test as the gold standard. Am J Gastroenterol 1996;91:2125-9.

56. Van Den Oever HLA, Loffeld RJLF, Stobberingh EE. Usefulness of a new serological test (Bio-Rad) to diagnose Helicobacter pylori-associated gastritis. J Clin Microbiol 1991;29:283-6.

57. Vandenplas Y, Blecker U, Devreker T, Keppens E, Nijs J, Cadranel S, PipeleersMarichal M, Goosens A, Lauwers S. Contribution of the 13C-urea breath test to the detection of Helicobacter pylori gastritis in children. Pediatrics 1992;90:608-11.

Recebido em 27/3/2001. Aprovado em 18/10/2001 